\title{
Effect Of Moisture Content On Some Engineering Properties Of Celosia Argentea Seed
}

\author{
Ilori, T.A., Akinyele, O.A. and Aremu, D.O. \\ (Department of Agricultural Engineering, Federal College of Agriculture, Ibadan, Oyo State, Nigeria)
}

\begin{abstract}
The Celosia Argentea is a tender and leafy vegetable, which is propagated by seed. There is dearth of information on it engineering properties needed for development appropriate handling of the seed. Bulk density, true density, porosity, angle of repose and coefficient of static friction on five structural surfaces (plywood, glass, mild steel, galvanized steel and stainless steel) were determined using standard methods. The moisture content was varied between 10.28 and $18.07 \%(\mathrm{db})$ across the properties studied. It was observed that within this moisture range, bulk density and true density decreased from 0.745 to $0.665 \mathrm{~g} / \mathrm{cm} 3$ and 1.454 to $1.387 \mathrm{~g} / \mathrm{cm} 3$ respectively. Within the moisture range of 10.28 and $14.07 \%(\mathrm{db})$, porosity slightly increased from 48.36 to $50.29 \%$ while it later decreased to $47.45 \%$ at $18.07 \%$ (db) moisture. Angle of repose increased from 15.36 to $21.88^{\circ}$ within the moisture range of $10.28-18.07 \%(\mathrm{db})$. The coefficient of static friction determined on five structural surfaces showed a decreased from 0.5229 to 0.2056 with increased moisture content for all the contact surfaces. There exist a strong relationship between the properties and the moisture content as expressed by the regression model.
\end{abstract}

Keywords: Celosia Argentea Seed, Structural Surface, Angle of Repose, Density

\section{Introduction}

Celosia Argentea is a tender and leafy vegetable rich in protein, vitamins and minerals belonging to a broad family of Amaranthaceae. It is known as Celosia, Lagos spinach, soko yòkòtò ("make husband fat" in Yoruba), áláyyohuó (in Hausa). The leaves are edible, are useful in soup, and stew preparations. The leaf and stem is cut into smaller sizes cooked with powdered melon, shrimps, fish, meat, sauce and seasoning ingredient to make a delicious Yoruba soup called 'Efo elegusi' which is eaten with cassava flour, pounded yam or rice.

Celosia Argentea seeds are extremely small; 1000-seed weight is $1.0-1.1 \mathrm{~g}$ [1].The flowers producing the seed are hermaphrodites. They are propagated by seeds grown on raised beds, ridges or flat beds either directly sown or transplanted. It grows best in full sunlight, well-drained area and tends to have short production cycles, require intensive labour but few purchased inputs [2]. Because of it high yields produce with strong nutritional value and demand, it is grown in large commercial quantity in Nigeria becoming a source of income for farmer especially during dry season. To promote food security and health related issue, the Federal Government of Nigeria introduce the dry season faming through its 'Fadama' farming programme with major focus on indigenous vegetable like Celosia Argentea.

Planting by broadcasting is a normal practice is south western Nigeria. These process waste seed and encourage high plant density, weed management and low yield. However, [3] recommend a spacing of $10 \mathrm{~cm} \mathrm{x}$ $10 \mathrm{~cm}$ for uniformity, crop management and high yield. To achieve this spacing, a planter needs to be developed. With large scale indigenous cultivation and high commercial demand of Celosia Argentea, some engineering properties of its seeds are important in many problems associated with the design of mechanized planter. The first point of call in the engineering properties is the physical properties which are basically dependent on some variables like moisture content. Moisture content is said to have a great influence on engineering properties biomaterial ([4],[5],[6], [7]). However, there is dearth of information on its engineering properties possibly because of the size and shape of the seed; this will enhance the development of machines to be used in processing into products, storage and handling of the seeds. The main objective of this study was to determine some engineering properties of Celosia Argentea seed, which would enhance the designing of specific machines for processing, storing and handling of the seeds.

\section{Methods And Material}

Freshly harvested Celosia Argentea seeds were sourced from Federal College of Agriculture, Moor Plantation, Ibadan, Nigeria and stored using black polythene bag kept inside a refrigerator until when used for this study. The engineering properties determined were moisture content, true density, bulk density, and porosity, angle of repose and coefficient of static friction. The methods adopted for estimating these engineering parameters are detailed as follows: 
- Moisture Content (MC): This was determined using [8] standard. The samples were weighed to the nearest $0.01 \mathrm{~g}$ by using electronic weighing balance (Mettler Toledo). Samples were oven-dried in Department of Agricultural Engineering, Obafemi Awolowo University, Ile-Ife laboratory oven (uniscope laboratory oven, model: Sm9053) at $105^{\circ} \mathrm{C}$ for 24 hours and afterwards, cooled in a desiccator and reweighed. Moisture content was expressed in dry basis using the equation (1):

$$
M_{c}(\% d b)=\frac{W_{w}-W_{d}}{w_{d}} \times 100
$$

Where: is the Mass of the sample before oven dried $(\mathrm{g})$, is the Mass of the sample after oven dried $(\mathrm{g}),(\% \mathrm{db})$ is the Percentage of moisture in the sample in dry basis

2.2Seed Conditioning: This study was carried out within the moisture range of $10.28-18.07 \% \mathrm{db}$. The amount of water added (Q) to condition the grains to the desired moisture level was determined by making use of Equation (2) :

$$
Q=\frac{A(b-a)}{100-b}
$$

Where: $\mathrm{Q}$ is the Mass of water to be added $(\mathrm{kg}), \mathrm{A}$ is the initial mass of sample (\%), a is the initial moisture content of sample $(\% \mathrm{db}), \mathrm{b}$ is the final (desired) moisture content of sample $(\% \mathrm{db})$..

2.3.Bulk density $\left(\rho_{b}\right)$ : The bulk density was determined using the mass/volume relationship [9]. Determination was by filling an empty topless cylindrical container of predetermined volume and tare weight with seed to the brim by pouring from a constant height, the top level was strike off and weighed. The measurement was replicated five times for each of the sample and computed using relation as follows:

$$
\mathrm{p}_{b}=\frac{\text { Mass of the Sample }(\mathrm{g})}{\text { Volume Occupied }\left(\mathrm{cm}^{3}\right)}
$$

2.4.True Density $(\rho \mathrm{t})$ : The true density (particle density) is defined as the ratio of the given mass of a matter to its volume. The volume and hence the density was determined by water displacement method as described by [10]. A measuring cylinder was filled with toluene to certain level, about 10grams of Celosia Argentea seed and known mass was submerged in the cylinder resulting in rise in the level of toluene. The true density was thus calculated for each of the five replications from the relation as follows:

$$
\rho_{t}=\frac{\text { Mass of the Samples }(\mathrm{g})}{\text { Volume of Water Displaced }\left(\mathrm{cm}^{3}\right)}
$$

2.5.Porosity: Porosity is the fraction of the space in the bulk grain which is not occupied by the grain. It is a property of the grain, which depends on its bulk and particle density. It was calculated from the percentage average values of bulk and true densities. The porosity was computed using the relation given by Equation (5):

2.6.Angle of repose $(\theta)$ : The dynamic angle of the repose was determined using a squarely constructed box as described by [11]. The box was filled with seed and the front panel was quickly removed which allows the seed to flow to its natural slope. The angle of repose was calculated from tangent inverse of ratio of the height to the base of the pile, which is given as Equation (6):

$$
\theta=\tan ^{-1}\left(\frac{h}{i}\right)
$$

Where: is the angle of repose (degrees), $h$ is the height of the free surface of the seeds and $l$ is the length of the heap formed outside the box.

2.7. Coefficient of Static Friction: The coefficients of static friction $(\mu)$ of the samples were determined on five surfaces (plywood, mild steel, galvanized steel, glass and stainless steel). The samples were place on inclined plane apparatus and an incorporated screw jack was gently tilted to the table until the frictional force between the sample and the surface was overcome by gravity and just start to moved down the slope. The angle of inclination was read from the graduated protector attached to the sliding table. This was replicated five times each for different surfaces. This is computed from Equation (7):

$$
\mu=\tan \theta
$$

Where: is the coefficient of static friction and is the angle of tilt in degrees

\section{Results And Discussion}

The summary of results for bulk density, true density and porosity at different moisture content level are presented in Table 1

3.1.Bulk Density:The bulk density of Celosia Argentea seed decreased from 0.745 to $0.665 \mathrm{~g} / \mathrm{cm}^{3}$ as the moisture level increased from 10.28 to $18.07 \%(\mathrm{db})$ (Table 1). The reduction in the bulk density at high moisture content could be attributed to the fact that an increase in mass due to moisture gain in the sample was lower than the accompanying volumetric expansion of the seeds [12]. Similar decreasing trend in bulk density has been 
reported by [13] for Pea seed, [14] for some legumes seeds, [15] for millet and [12] for karanja kernel. Logarithmic relationships described the bulk density ( dependence of moisture content MC, as shown below: $\rho_{b}=-0.052 \ln M C+0.7441\left(R^{2}=0.9842\right)$

The knowledge of bulk density are needed in determination of the weight of seeds in the hopper. The bulk density of seeds is also useful in the design of silos and storage structures.

3.2.True Density: The true density of Celosia Argentea seed decreased from 1.454 to $1.387 \mathrm{~g} / \mathrm{cm}^{3}$ as the moisture content increased from 10.28 to $18.07 \%(\mathrm{db})$ (Table 1). The result of true density (greater than density of water that is $1 \mathrm{~g} / \mathrm{cm}^{3}$ ) indicates that the seed is heavier than water hence the seeds will not float in water. A similar trend of true density for other seed also was found for pomegranate seed [16] and Tef seed [17]. The moisture dependence of the true density was described by a linear equation as follows:

$\rho_{t}=0.044 M_{c}+1.5034\left(R^{2}=0.9823\right)$

This knowledge is useful in the design of cleaning and separation machines and also relatively useful in computing product yield and throughput in processing machinery.

3.3.Porosity: The porosity of Celosia argentea seeds was found to increase, initially from 48.36 to $50.29 \%$ at moisture range of 10.28 to $14.07 \%(\mathrm{db})$ and later decreased to $47.45 \%$ at $18.07 \% \mathrm{db}$ moisture as shown in Table 1. The result shows a non-linear relationship of porosity with moisture content. This could be attributed to the expansion and swelling of seeds that might have created more voids between the seeds and increased bulk volume. This is also exhibited in the reduction of bulk density with an increase in moisture content. Many researchers such as [18] (millet) observed a related trend of increase in porosity with increase in moisture content.The values of porosity are dependent on the bulk and true densities. The variation in porosity $P$ with respect to varying moisture content can be represented by the following polynomial equation.

$$
P=0.0045 M C^{a}-0.5826 M C^{2}+3.1281 M C+45.775 \quad\left(R^{2}=0.9739\right)
$$

Data on porosity are needed in the design of aeration systems during storage and the number of seeds that will enter a hollow seed tube of the planter.

3.4. Angle of Repose: The effect of moisture content on the angle of repose of Celosia Argentia seeds are shown in Figure 1. The angle of repose of Celosia Argentia seed was found to increase as the moisture content also increases. The values of angle of repose increased from 15.36 to $21.88^{\circ}$ as against the moisture content from 10.28 to $18.07 \%(\mathrm{db})$. This increasing trend of angle of repose with moisture content occurs because surface layer of moisture surrounding the particle hold the aggregate of sees together by the surface tension [12]. Related trends were observed by [19] for faba bean grains, and [20] for Jatropha seed. The angle of repose for Celosia Argentia seed showed exponential relationships with moisture content:

$\theta=13.811 e^{0.0924 M C}\left(R^{2}=0.9701\right)$

Data on angle of repose may be used to design size of conveyor belt for transporting agricultural materials and also useful for design of hopper.

3.5. Coefficient of Static Friction:The coefficient of static friction of Celosia Argentia seed on the five structural surfaces (plywood, glass, mild steel, galvanized steel and stainless steel) against moisture content in the range of 10.28 to $18.07 \%$ (db) was found to decrease in Figure 1. It was observed that the coefficients of static friction decreased with increase in moisture content for all contact surfaces. The coefficient of static friction of Celosia argentea seed is a function of its angle of inclination. The decrease in friction coefficients at high moisture content may be because the surface of the seeds got smoother at high moisture content and the sliding characteristic of the seeds improved. At all moisture content, the maximum friction was offered by plywood while the minimum friction was observed with stainless steel.

The least static coefficient of friction may be owing to smooth surface of the stainless steel. However, [21] observed similar trends for Sorghum seeds, [12] for pigeon pea, linseed and fuzzy cotton seed([22];[23]). The relationships between coefficient of static friction and the moisture content on plywood $(p)$, glass $(g)$, mild steel $(m)$, galvanized steel $(g s)$ and stainless steel $(s)$ can be represented by the following linear equations:

$$
\begin{aligned}
& \mu_{p}=-0.0309 M_{c}+0.5564\left(R^{2}=0.9715\right) \\
& \mu_{g}=-0.0281 M_{c}+0.4044\left(R^{2}=0.9791\right) \\
& \mu_{m}=-0.0219 M_{c}+0.4596\left(R^{2}=0.9794\right) \\
& \mu_{g s}=-0.0276 M_{c}+0.5138\left(R^{2}=0.8877\right) \\
& \mu_{g}=-0.0291 M_{c}+0.3532\left(R^{2}=0.9903\right)
\end{aligned}
$$

Data on coefficient of friction is useful in the design of hopper and in selecting appropriate materials for different units of machinery especially the components requiring flow of the seeds. The design of the 
container for storage such as silo and for loading and unloading during handling such as hopper is dependent on the knowledge of the friction properties.

\section{Conclusion}

The conclusion drawn from the research on effect of moisture content on some engineering properties of Celosia Argentia seed showed that bulk and true density decreased with increase in the moisture content while porosity showed a non-linear relationship. The angle of repose was found to increase with increased moisture content. The coefficient of static friction of Celosia Argentea seed decreased in order of plywood, galvanized steel, mild steel, glass and stainless steel with increase in moisture content. The research revealed that there are differences in size characteristics of Celosia argentea seed and also there was a huge variability in moisture content among the samples at initial condition. The work provides a database for the design and construction of processing and storage equipment.

Table 1: Density and Porosity properties of Celosia Agentia seed at different moisture content

\begin{tabular}{lllll}
\hline & \multicolumn{4}{c}{ Moisture content $(\% \mathrm{db})$} \\
\cline { 2 - 5 } Properties of Seed & \multicolumn{1}{c}{10.28} & 12.08 & 14.07 & 16.07 \\
\hline Bulk Density (g/cm3) & $0.7454 \pm 0.0032 *$ & $0.7068 \pm 0.0081$ & $0.6873 \pm 0.0039$ & $0.6746 \pm 0.0013$ \\
True Density (g/cm3) & $1.4541 \pm 0.1404$ & $1.4116 \pm 0.1305$ & $1.3869 \pm 0.0877$ & $1.3291 \pm 0.1918$ \\
Porosity (\%) & $48.36 \pm 0.04 .83$ & $49.56 \pm 4.88$ & $50.29 \pm 3.20$ & $48.39 \pm 8.10$ \\
\hline
\end{tabular}

\section{*standard deviation}

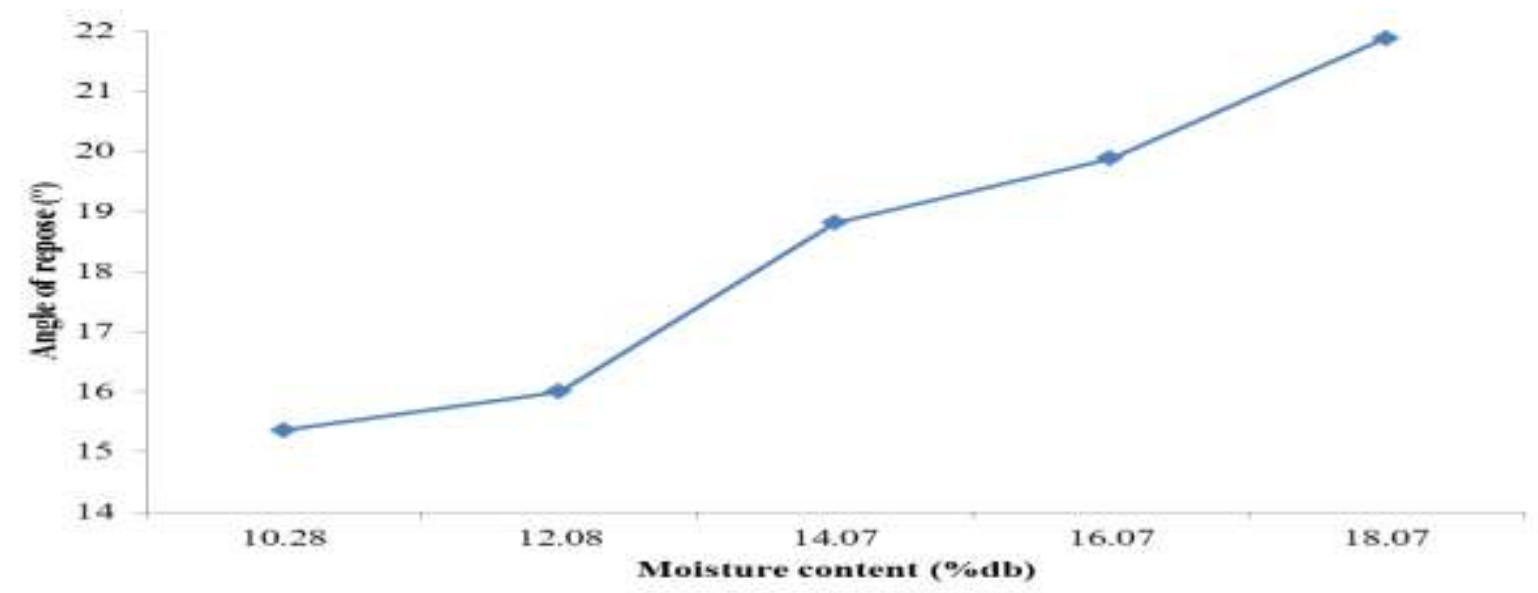

Figure 1: Effect of Moisture Content on Angle of Repose of Celosia Argentia Seed

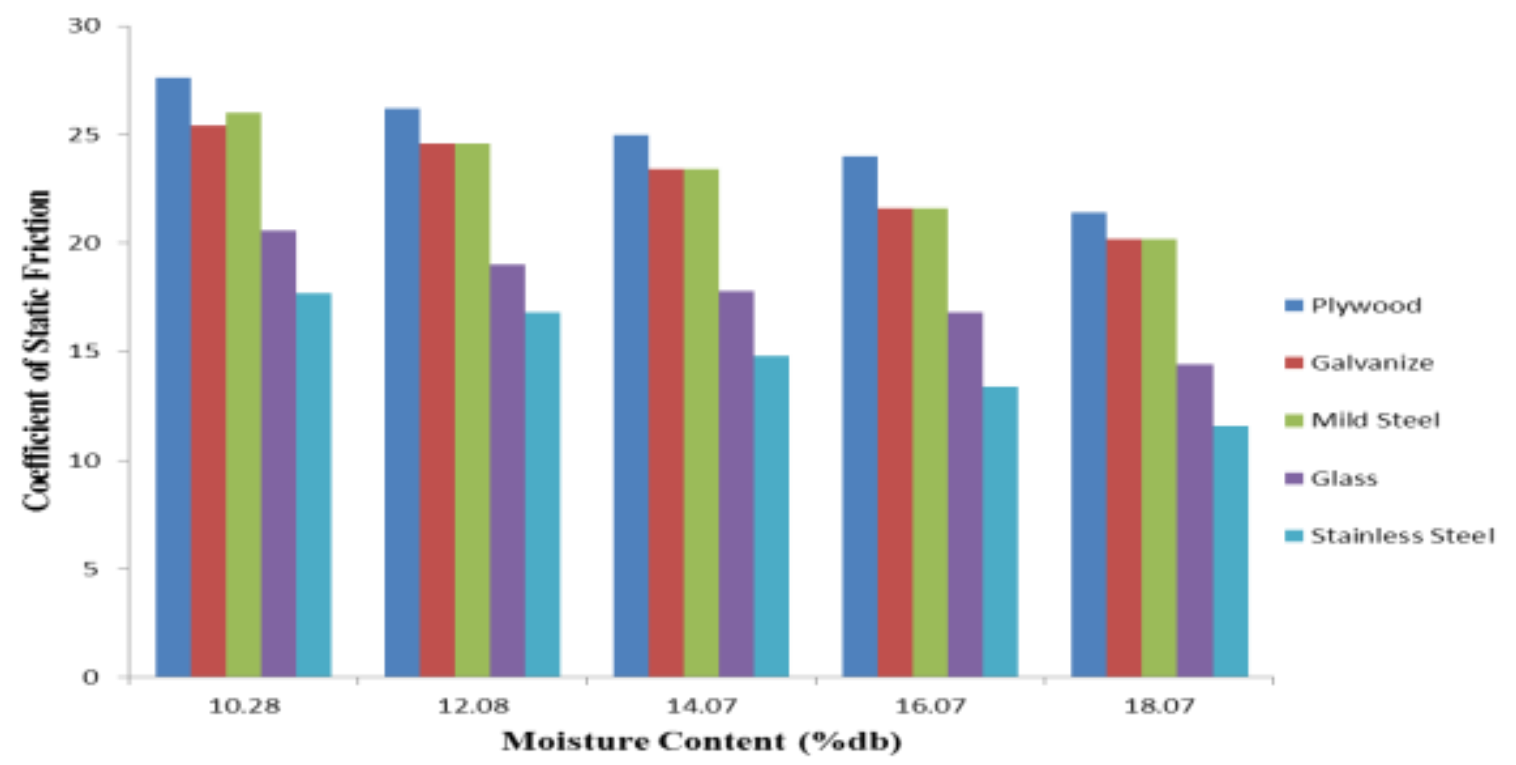

Figure 2: Effect of Moisture Content on Coefficient of Static Friction of Celosia Argentia Seed. 


\section{References}

[1 ]. Denton, O.A. Celosia Argentea L. [Internet] Record from PROTA4U. Grubben, G.J.H. \& Denton, O.A. (Editors). PROTA (Plant Resources of Tropical Africa/ Resources végétales de l'Afrique tropicale), Wageningen, Netherlands. <http://www.prota4u.org/search.asp>.(2004).

[2 ]. Schippers, R.R.. African Indigenous Vegetables: An Overview of the Cultivated Species, University of Greenwich, Natural Resources Institute, London, UK $222: 220.2000$

[3 ]. Akanbi, W.B., Baiyewu, R.A., Tairu, F.M. Effect of Organic Based Fertilizer and Spacing on Growth and Yield of Celosia (C .Argentea L.). Journal of Agriculture. Forestry and. Fish., 1(1) , 2000,5-10.

[4 ]. Kaleemullah S. and J. J. Gunasekar. Moisture-Dependent Physical Properties of Arecanut Kernels. Biosystems Engineering., 82(3),2002, 331-338.

[ 5]. Nimkar P. M. and P. K. Chattopadhyay. Some Physical Properties of Green gram. Journal of Agricultural Engineering Research, 80(2),2001,183-189.

[6 ]. White, N.D. G. and D.S. Jayas. Physical Properties of Canola and Sunflower Meal Pellets. Canadian Biosystems Engineering 43 ,2001, 349-352

[7 ]. Tunde-Akintunde, T.Y. and B.O. Akintunde. Effect of Moisture Content and Variety of Selected Properties of Beniseed. Agricutural Engineering International: The CIGR E-Journal Manuscript FPO7021, IX, 2007.

[8 ]. AOAC, 2002. Standard Official Methods of Analysis of the Association of Analytical Chemists, 13th Edition, Washington D.C.

[ 9]. Ogunsina, B. S., Olaoye, I. O., Opeyemi, O. O. and A. O Adegejo. Some Nutritional Physical Properties of Sponge Gourd Seeds. Proc. 3rd International Conference of WASAE and 9th International Conference of NIAE,2009, 198.

[10 ]. Ilori, T.A. and Raji, A. O. Some Engineering properties of Tomateos. International journal of engineering research and Application. 3(1),2013, 1655-1661.

[11]. Ilori, T.A., Raji, A. O. and Dauda, T.O. Evaluation of some physical and thermal properties of Thevetia peruviana as affected by days of havest. International journal of scientific and engineering research . 4(1), ,2013, 1-8.

[12]. Pradhan, R.C., S.N. Naik, N. Bhatnagar, Swain, S.K.. Moisture-dependent physical properties of Karanja (Pongamia pinnata) kernel. Industrial Crops and Products, 28(2) , 2008,155-161.

[13]. Yalçin, İ., C. Özarsalan. and T. Akbaş. Physical Properties of Pea (Pisum sativum) seed. Journal of Food Engineering, 79(2), 2007, 731-735.

[14]. Altuntaş, E. and Demirtola, H. Effect of moisture content on physical properties of some grain legume seeds. N. Z. Journal of Crop Horticulture Science, 35(4), 2007, 423-433.

[15]. Singh, K.P., Mishra, H.N. and S. Saha. Moisture-dependent properties of barnyard millet grain and kernel. Journal of Food Engineering. 96,2010,598-606.

[16]. Kingsly, A.R.P. Moisture dependent physical properties of dried pomegranate seeds (Anardana). Journal of Food Engineering, 75(4),2006, 492-496.

[17] Zewdu, A.D., Solomon, W.K. Moisture-Dependent Physical Properties of Tef Seed. Biosystems Engineering, 96(1)(2007, 57-63.

[18]. Baryeh, E.A. and Mangope, B.K. Some physical properties of QP-38 variety pigeon pea. Journal of Food Engineering, 56, 2002, 59-65.

[19]. Altuntaş, E. and Yildiz, M. Effect of moisture content on some physical and mechanical properties of faba bean (Vicia faba L.) grains. Journal of Food Engineering, 78, 2007, 174-183.

[20]. Garnayak, D.K., R.C. Pradhan, S.N. Naik and Bhatnagar, N. Moisture-dependent physical properties of Jatropha seed (Jatropha curcas L.). Ind. Crops and Products, 27, 2008, 123-129.

[21]. Gikuru, M. and M. S Mark. Effect of Moisture Content on the Physical Properties of Three Varieties of Sorghum Seeds. J of Food Engineering, 75, 2006, 480-486.

[22]. Selvi, K.C. Some physical properties of linseed. Biosystem Engineering, 95(4), 2006, 607-612.

[23]. Manimehalai N. and R. Viswanathan (2006). Physical properties of fuzzy cottonseeds. Biosystem. Engineering. 2006; 95:207-217. 